\title{
LA DAFNE DE RINUCCINI Y LA DE OPITZ: EL COMIENZO DE LA ÓPERA ITALIANA Y ALEMANA. EDICIÓN BILINGÜE
}

M. a Dolores Castrillo de Larreta-Azelain

UNED. Madrid

mcastrillo@flog.uned.es

MARINA SANFILIPPO UNED. Madrid

msanfilippo@flog.uned.es

\section{RESUMEN}

Edición bilingüe de los libretos de la Dafne de Rinuccini-Peri y de la de OpitzSchütz.

Palabras Clave: Mitología Clásica, Recepción Clásica, Libretología, Ópera, Dafne, Rinuccini, Opitz.

Abstract

Bilingual edition of the libretti of Daphne by Rinuccini-Peri and by Opitz Schütz.

KEY WORDs: Mythology, Classical Reception, Librettology, Opera, Daphne, Rinuccini, Opitz.

1. Sobre el nacimiento de la Ópera hay ya asentimiento general: es una de las últimas manifestaciones del Renacimiento, esa etapa de la cultura occidental empeñada en 
hacer renacer la tradición cultural del Mundo Clásico, en esta ocasión en el campo de la música vocal, en la que texto y música se funden en un excelente producto resultante. Más concretamente, se pretendía recuperar la vieja Tragedia griega, esa variante teatral que gozó de un notable prestigio en la Antigüedad grecolatina, y en la que igualmente se fundía ambos elementos. En la práctica, lo que sucedió es que, con la pretensión de alcanzar la meta teórica mencionada, se fue dando una mayor envergadura a unidades musicovocales más breves, como los madrigales y, sobre todo, los intermedii, hasta llegar a la amplitud requerida para tener la entidad de una obra de teatro autónoma.

También es bien sabido que todo esto sucede en la Florencia del último decenio del s. XVI, en el entorno de la Camerata Fiorentina sostenida por el conde Bardi, al que sustituirá en los años '90 el joven noble Jacopo Corsi. En ese contexto se encarga a Ottavio Rinuccini que escriba una acción dramática de cierta extensión sobre el tema mitológico de Dafne y, sobre todo, en la línea que venía debatiéndose en la Camerata. La música correrá a cargo de Jacopo Peri. Se estrenó en 1597, o más probablemente a principios de 1598, y alcanzó gran éxito, reponiéndose al año siguiente y dos veces en 1600, año este último que verá ya subir a los escenarios varias óperas. Había empezado la historia de la Ópera.

2. Con frecuencia se lee en los Manuales al uso el lamento de que, desgraciadamente, la Dafne de Rinuccini / Peri se ha perdido, pero es una verdad a medias. Conservamos el texto, que es la mitad del total. Y desde el punto de vista literario es una joya porque tenemos delante el primer intento de crear una nueva variante teatral, la obra dramática cantada.

El acercamiento filológico a la parte textual de los libretos operísticos se ha consolidado en los últimos decenios de forma rotunda, con especial intensidad desde los años noventa del siglo pasado. La filología alemana ha creado un nuevo término, die Librettologie, que ha ocupado su sitio incluso en las páginas divulgativas de Internet ${ }^{1}$, y que apuesta por el análisis literario de los textos musicados.

3. En el caso de esta Dafne de Rinuccini ya se ha dicho que con ella, por ahora, arranca la historia de la Ópera italiana, y de la Ópera en general. Pero, curiosamente, va a ser también la obra con que dará comienzo la Ópera alemana: el poeta alemán Martin Opitz von Boberfeld (1597-1639), considerado el padre de la poesía barroca alemana, escribe una Dafne que, musicada por Heinrich Schütz (1585-1672), se convertirá en la primera ópera alemana, estrenada el 13 de abril de 1627 en el castillo de Hartenfels en Torgau.

La música de Schütz también se ha perdido, pero no así el libreto de Opitz, del que suele decirse que es una traducción del texto de Rinuccini, lo que supone una nueva imprecisión. En este trabajo se editan en paralelo los dos textos, con sus traducciones respectivas al español. Una lectura sencilla de ambos textos deja ver que Opitz tuvo

\footnotetext{
${ }^{1}$ http://de.wikipedia.org/wiki/Librettologie: «Die Librettologie ist eine relativ junge literaturwissenschaftliche Forschungsdisziplin. Sie beschäftigt sich mit dem Libretto (d.h. mit Texten von Opern, Oratorien, Kantaten u.ä.) nicht aus musikwissenschaftlicher, sondern aus literaturwissenschaftlicher Sicht. Der Text (sofern es nicht ein vertonter kanonischer Text beispielsweise der Liturgie ist) wird dabei nicht mehr als reiner Träger von Musik und Handlung gesehen, als ,,der Musik gehorsame Tochter«, wie Mozart es nannte, sondern als eigene literarische Gattung im Spannungsfeld zwischen literarischen, dramaturgischen und musikalischen Anforderungen...» (consultado el 25 de noviembre de 2013).
} 
delante la obra del italiano, pero también que su labor fue una recreación personal, dado que se separa constantemente del modelo. En el Acto V cambia incluso de manera radical la forma del desenlace: Rinuccini, fiel al modelo de la Tragedia griega, hace entrar a un Mensajero que nos narra de manera indirecta la metamorfosis de Dafne, mientras que Opitz decide hacerlo de forma directa con la intervención de los propios personajes; en consecuencia, no hay paralelismo alguno entre una y otra obra a lo largo del desenlace propiamente dicho, y solo vuelven a una senda próxima en la intervención final del coro, que cierra la acción dramática general. 


\section{LA DAFNE}

Ottavio Rinuccini

Jacopo Peri - Jacopo Corsi

Interlocutori

Ovidio

Venere

Amore

Apollo

Dafne

Nunzio

Pastori

Ninfe

Coro

\section{DAFNE}

Ottavio Rinuccini

Jacopo Peri - Jacopo Corsi

Personajes

Ovidio

Venus

Amor

Apolo

Dafne

Mensajero

Pastores

Ninfas

Coro 


\section{LA DAFNE}

Martin Opitz

Heinrich Schütz

Personen des Gedichtes

Ovidius - Vorreder

Dafne

Apollo

Venus

Cupido

Der erste Hirt

Der ander Hirt

Der dritte Hirt

Chor der Hirten

Chor der Nymphen und Hirten

\section{DAFNE}

Martin Opitz

Heinrich Schütz

Personajes del Poema

Ovidio - Prologuista

Dafne

Apolo

Venus

Cupido

Primer pastor

Segundo pastor

Tercer pastor

Coro de pastores

Coro de ninfas y pastores 


\section{PROLOGO}

Scena unica

\section{OVIDIO}

Da' fortunati campi, ove immortali

godonsi all'ombra de' frondosi mirti

i graditi dal ciel felici spirti, mostromi in questa notte a voi mortali.

Quel mi son io, che su la dotta lira cantai le fiamme celesti de' celesti amanti e i trasformati lor vari sembianti soave sì, ch'il mondo ancor m'ammira.

Indi l'arte insegnai come si deste, in un gelato sen fiamma d'amore, e come in libertà ritorni un core cui son d'amor le fiamme aspre, e moleste.

Ma qual par che tra l'ombre, e 'l ciel rischiari

nova luce, e splendor di rai celesti qual maestà vegg'io? Son forse questi gl'eccelsi augusti miei felici, e chiari?

Ah riconosco io ben l'alta regina gloria, e splendor de' lotaringi regi il cui nome immortal gl'alteri fregi

celebra '1 mondo, e "1 nobil Arno inchina.

Seguendo di giovar l'antico stile con chiaro esempio a dimostravi piglio quanto sia donne, e cavalier periglio la potenza d'amor recarsi a vile.

Vedrete lagrimar quel dio ch'in cielo reca in bel carro d'or la luce, e '1 giorno,

e dell' amata ninfa il lume adorno adorar dentro al trasformato stelo.

\section{PRÓLOGO}

Escena única

\section{OVIDIO}

Desde los campos afortunados, donde inmortales

gozan bajo la sombras de los mirtos frondosos

las almas felices que agradan a los dioses me manifiesto esta noche ante vosotros los mortales

Ese soy yo que en la docta lira canté el fuego de los amantes celestes y sus varias transformadas apariencias de forma tan suave que el mundo todavía me admira.

Después enseñé el arte, como se despierta en un pecho helado fuego de amor y como vuelva a la libertad un corazón al que el fuego de amor resulte agrio y molesto.

Pero ¿quién aparece, desprendiendo entre las sombras y el cielo nueva luz y esplendor de rayos celestes? ¿Qué majestad veo yo? ¿Quizá estos son mis excelsos Augustos felices y claros?

Ah, bien reconozco yo la alta Reina, gloria y esplendor de los Reyes Lotaringios cuyo nombre inmortal, las nobles cualidades,

celebra el mundo, y el noble Arno se inclina.

Aprovechando el antiguo estilo, con claro ejemplo empiezo a demostraros lo peligroso que es, Damas y Caballeros, la potencia de Amor envilecer.

Veréis llorar a ese Dios, que en el cielo lleva en bello carro de oro la luz y el día,

$\mathrm{Y}$ adorar dentro del trasformado tallo de la amada Ninfa la hermosa luz. 


\section{Der Vorreder}

\section{Ovidius}

Ihr sterbliches Volk! Der ich nicht sterblich bin

Komm' jetzt zu euch von den Opfer

Feldern,

Wo unsre Geister ziehen hin

Und legen sich in grünen Wäldern;

Durch des bleichen Charons Meer

Komm`ich, o ihr Menschen, her.

Ich bin der Mann, der ich so rühmlich sang

In meine Harf' und die berufnen Zeiten, Wie Amors Macht und harter Zwang

Den himmlischen vor alten Zeiten

Hat verwandelt die Gestalt

In Geflügel, Wild und Wald.

Ich habe mich die schwere Liebeskunst,

O dich, mein Rom, zu lehren unternommen;

Hab' auch gezeigt, wie solcher Brunst

Ein Herze wieder ab sol kommen.

$\mathrm{Da}$ man recht liebt, kömt durch mich,

$\mathrm{Da}$ man nicht liebt, thu' auch ich.

Schau' aber zu, was für ein heller Schein

Umgibt mich doch, und wessen werd' ich innen?

Was Majestät muß dieses sein,

Die mir bescheint Gesicht und Sinnen?

Was doch blinket für ein Licht?

Ist es mein Augustus nicht?

Ich kenne dich, du Blume dieser Zeit,

Du Zier und Spiegel aller Jugend:

Der Rautenkranz, die Freundlichkeit

verräthet dich, o Glanz der Tugend.

Alle Menschen loben dich,

und die Elbe neiget sich.

Du edle Brau, wol deiner Lieb’ und dir!

Ich aber will jetzt, wie vorweilen, singen,

In was für Noth ein Cavalier

Und eine Dame sich kan bringen,

Die nicht nach der Liebe fragt,

Und nur thut, was ihr behagt.

Ihr werdet sehn für schwerer Liebespein,

Denselben Gott mit nassen Seufzen klagen,

Der uns den schönen Tagesschein

herum führt auf dem güldnen Wagen,

Der uns allen gibt das Licht;

Sieht für Liebe selber nicht.

\section{El prologuista}

\section{Ovidio}

¡Pueblo mortal! El que no lo es acude a vosotros desde los campos del sacrificio,

hacia donde parten nuestros espíritus

y yacen en verdes bosques:

a través del pálido mar de Caronte

yo acudo, o vosotros, los hombres.

Yo soy ese hombre, que tan notoriamente cantó

con mi arpa y en los tiempos sonados

cómo el poder del Amor y la absoluta necesidad

transformaron los cuerpos celestes de

tiempos remotos en aves, venados y

bosques.

Me he propuesto enseñarte el difícil arte amatorio

a ti, Roma mía;

mostré también cómo ese celo

puede recuperar de nuevo un corazón.

que bien se ame, pasa a través de mí, que no se ame, es también debido a mí.

Pero contempla qué luz tan clara

me rodea, y ¿quién está entrando en mí?

¿Qué Majestad ha de ser ella

que me ilumina rostro y sentidos?

Mas, ¿qué es esa luz que brilla?

¿No se trata de mi Augusto?

Te conozco, flor de este tiempo, adorno y espéculo de toda juventud,

la corona de macia, la gentileza

te delatan, oh, reflejo de virtud.

Todos los hombres te alaban

y el Elba se inclina ante ti.

Novia egregia, deseo el bien para tu amor y para ti!

Mas ahora, como antes, deseo cantar

las miserias que han de padecer un caballero

y una dama que no busca el amor

y tan sólo hace lo que le place.

Veréis por hondas penas de amor

al mismo Dios llorar con húmedos gemidos.

El mismo que la cálida luz del día

nos regala en su carro de oro,

El mismo que a nosotros nos da la luz

para sí el amor no halla. 


\section{ATTO UNICO}

Scena unica

\section{CORO}

Tra queste ombre segrete

s'inselva e si nasconde

l'orrida belva; cauti 'l piè movete

ninfe e pastori, ah non scotete fronda.

\section{PASTORI}

Dunque senza timor, senza spavento pe' nostri dolci campi

non guiderem mai più gregge od armento?

CORO

Giove immortal, che tra baleni e lampi

scoti la terra, e ' 1 cielo,

mandane o fiamma, o telo

che da mostro sì rio n'affidi, e scampi.

\section{NINFA}

E quando mai per queste piagge e quelle fronda corremo o fiore,

misere verginelle;

che di terror non ci si agghiacci ' 1 core?

\section{CORO}

Ebbra di sangue in questo oscuro bosco giacea pur dianzi la terribil fera.

ECO: Era.

CORO

Dunque più non attosca

nostre belle campagne altrove è gita?

ECO: Ita.

\section{CORO}

Farà ritorno più per questi poggi?

ECO: Oggi.

CORO

Ohimè chi n'assicura

s'oggi tornar pur deve il mostro rio?

ECO: Io.

\section{CORO}

Chi sei tu che ne assicuri, e ne console?

ECO: Sole.

CORO

Il sol tu sei? Tu sei di Delo il dio?

ECO: Dio.

CORO

Hai l'arco teco per ferirlo Apollo?

ECO: Hollo.

\section{CORO}

S'hai l'arco tuo saetta infin che mora questo mostro crudel, che ne dimora.

\section{ACTO ÚNICO}

Escena única

\section{CORO}

Entre estas sombras secretas se enselva, y se esconde

la horrible bestia, con cautela moved el pie,

ninfas y Pastores; ah no agitéis las frondas.

\section{PASTORES}

¿Por tanto sin temor, sin espanto, por nuestros dulces campos ya no volveremos a llevar grey o rebaño?

\section{CORO}

Júpiter inmortal, que entre rayos y

relámpagos

estremeces la Tierra y el Cielo,

mándanos o llama o dardo

que de un monstruo tan malvado nos tutele y salve.

\section{NINFAS}

¿Y cuándo por estas playas y esas

frondas correremos, oh flor,

pobres virgencitas,

sin que de terror se nos hiele el corazón?

\section{CORO}

Ebria de sangre en este bosque oscuro sin embargo yacía antes la fiera terrible.

\section{CORO}

¿Entonces ya no aflige

nuestras hermosas campiñas? ¿Se ha ido a otro lugar?

\section{CORO}

ECO:... ible.

¿Volverá un día por estos lares?

ECO:... ugar.

ECO:....ares.

\section{CORO}

¡Ay de nosotros! ¿Quién nos ofrece seguridad si hoy tiene que volver el monstruo malvado?

ECO:... ado.

\section{CORO}

¿Quién eres tú que das confianza y consuelo?

ECO:...uelo.

CORO

¿Eres tú el Sol? ¿eres el dios de Delos?

ECO:...elos.

\section{CORO}

Llevas contigo el arco para herirlo, Apolo?

\section{CORO}

Si tienes tu arco, disparas dardos hasta que muera este monstruo cruel que nos devora. 


\section{DER ERSTE ACT.}

DER ERSTE HIRT.

Unter diesem Schatten hier liegt das grimme Wunderthier; Ihr Hirten weicht, geht weg, ihr Schäferinnen;

Schaut, daß kein Ast sich nicht bewegt, Daß kein Geräusche sich erregt, Es wird sonst euer innen.

DER ANDERE HIRT

So müssen wir dann aus Gefahr

Die süßen Felder meiden

Und können unser Vieh und weißen

Lämmer Schar

Nicht sicher weiden?

DER DRITTE HIRT

O Jupiter, der uns mit Donnerflammen erschüttert See und Land,

Nim deinen Blitz und Hagel ganz

zusammen

Beut her die starke Hand

Komm uns Armen doch zu Steuer

Wider dieses Ungeheuer.

DER ERSTE HIRT.

Um diesen Wald und Schatten haben wir bisher gesehn das blutgekränkte Thier.

ECHO. hier.

Wie, daß ich jetzund sicher bin?

Ists weg, ists anderswo dann bin?

ECHO. bin.

Ich weiß nicht, wie ich doch dies Ebenteuer beute

Kömt es inkünftig auch noch wieder für uns Leute?

ECHO. heute.

Ach! Ach! Wer dann tröstet mich,

Wann das Thier lasset sehen sich?

ECHO.Ich.

Wer bist du, welcher mir verbeischt so große Wonne?

$\mathrm{O}$ bester Trost, den je beschienen hat die Sonne!

ECHO. Die Sonne.

Bist du der Gott aus Delos, welcher sich

Mir zeigen will? O Sonne, hör' ich dich?

ECHO. Ich dich.

$\mathrm{Du}$, du hast Pfeil und Kraft; drumm steure der Gewalt

Der grimmen Bestien, o Phöbus, also bald.

\section{ACTO PRIMERO}

\section{EL PRIMER PASTOR}

Bajo esta sombra de aquí yace el prodigio de furia vosotros, pastores, retroceded, huid pastoras;

Velad porque ni una rama se mueva, que no se escuche ni ningún sonido, para que de vuestra presencia no se percate.

\section{EL SEGUNDO PASTOR}

Por este peligro hemos de evitar los dulces campos,

¿no pueden pastar, pues, nuestro ganado ni nuestros

blancos rebaños de ovejas seguros?

\section{EL TERCER PASTOR}

Júpiter, que con rayos y truenos haces temblar el mar y la tierra, captura tus relámpagos y granizo

coge tu robusta mano

y guíanos a los pobres de nosotros, contra este monstruo.

\section{EL PRIMER PASTOR}

Por este bosque y en la sombra hemos visto hasta ahora al sanguinario animal.

ECO. ...mal.

¿Cómo es que ahora me siento seguro?

¿Se fue, o es que en otro lugar estoy?

ECO. Estoy

No sé cómo a este monstruo apresar voy ¿si regresara en el futuro de nuevo a nosotros?

$$
\text { ECO....otros. }
$$

¡Ay, ay! Quién me consolará, cuando el animal se deje ver?

ECO....ver.

¿Quién eres tú que tal deleite me proporciona?

¡Oh máximo consuelo iluminado por el sol!

Eres el dios de Delos, el que se me

ECO. El sol. quiere mostrar? Sol, ¿te estoy escuchando a ti?

ECO. A ti.

Tú, tú tienes la flecha y la fuerza, por ello guía la violencia de las bestias furiosas, $\mathrm{O}$ Febo, y pronto.

ECO. Pronto. 
Qui Apollo mette mano all'arco e saetta il Fitone.

\section{APOLLO}

Poi giacque estinto al fine in sul terren sanguigno

dall'invitt'arco mio l'angue maligno

securi itene al bosco

ninfe, e pastori, ite securi al prato.

Non più fiamma, e tosco

infetta 'l puro ciel l'orribil fiato

tornin le belle rose

ne le guance amorose

torni tranquillo il cor sereno '1 volto

io l'alma, e 'l fiato al crudo serpe ho tolto.

\section{CORO}

Almo dio, che ' 1 carro ardente per lo ciel volgendo intorno vesti 'l dì d'un aureo manto; se tra l'ombra orrida algente splend'il ciel di lume adorno è pur tua la gloria, e il vanto. Se germoglian frondi, e fiori selve, e prati, e rinovella l'ampia terra il suo bel manto, se de' suoi dolci tesori ogni pianta si fa bella è pur tua la gloria, e il vanto. Per te vive, e per te gode quanto scerne occhio mortale o rettor del carro eterno ma si taccia ogn'altra lode sol de l'arco, e de lo strale voli il grido al ciel superno. Nobil vanto il fier dragone di velen, di fiamme armato sul terren versat'ha l'alma per trecciar fregi e corone al bel crin di raggi ornato qual fia degno edera, o palma?
Aquí Apolo coge el arco y dispara flechas contra Pitón

\section{APOLO}

Sin embargo yació extinguida por fin sobre la tierra sangrienta,

gracias a mi arco invicto, la serpiente

maligna.

Id seguros por el bosque,

ninfas y Pastores, id seguros por el prado.

Ya no infecta el cielo puro

el horrible aliento con llama y veneno

vuelvan las rosas hermosas

en las amorosas mejillas

vuelva la tranquilidad en los corazones, la serenidad en los rostros

Yo he quitado el alma y el aliento a la serpiente cruel.

\section{CORO}

Magnífico dios que, el carro de fuego llevando alrededor del cielo, vistes el día de un manto dorado, si entre la horrorosa sombra helada brilla el cielo adornado con una luz tuyos son también la gloria y el honor si brotan frondas y flores,

Bosques y prados, y renueva

La tierra su hermoso manto,

si con sus hermosos tesoros

todas las plantas se ponen guapas

tuyos son también la gloria y el honor.

para ti vive, y para ti goza

todo lo que percibe ojo mortal,

gobernador del carro eterno:

pero enmudezca cualquier otra alabanza;

solo vuele arriba hacia el cielo el grito

del arco y del dardo.

¡Noble gloria! El feroz Dragón

armado de veneno y llamas

en la tierra ha vertido el alma:

para trenzar lazos y coronas

al hermoso pelo adornado de rayos

¿cuál será digna, la hiedra o la palma? 
APOLLO

So ist denn nun dem Drachen

Durch meines Bogens Macht

Gestillt der Wilde Rachen?

Umringt ihn nun die Nacht,

Der vor die Pest der Erden

Die Scheu der Menschen war?

Ihr Hirten, bringt die Herden;

Ihr seid nun aus Gefahr.

Ihr Nymphen, windet Kränze,

hegt schöne Lobetänze,

Komt kühnlich in den Wald,

Singt, das die Heid erschallt.

Das Thier wird nicht forthin

Die Luft vergiften können,

Und Krankheit nach sich ziehn.

Erfrischet Herz und Sinnen

Die Wangen müssen nun euch nochmals nicht verbleichen,

Sie sollen Lilien und roten Rosen gleichen;

Dann die Schlang ist umgebracht,

Die euch Kummer hat gemacht.

\section{CHOR DER HIRTEN}

Du großer Gott, der du den Feuerwagen

Ringsum den schönen Himmel führt,

Der du den Tag, so oft es pflegt zu tagen,

Mit einem güldnen Mantel zierst,

Daß der helle Schein sich bringet

Durch der finstern Nächte Ruh,

Daß uns klares Licht umringet,

O Apollo; das machst du.

Daß aus den Frost dies große Rund der

Erden

Sein graues Winterkleid ablegt,

Daß Wiesen, Feld und Wald verjünget

werden,

Daß des Geflügels Heer sich regt,

Daß sie in den Lüften fliegen

Und uns lieblich singen zu;

$\mathrm{Da}$ die Bäume Blätter kriegen,

O Apollo, das machst du!

Du Künste-Gott, du Arzt, du

Traumausleger,

Du Sengerfürst, du Krauspenhaar,

Du Immer-jung, du Meister aller Jäger

Von dir kömt alles ganz und gar;

Doch dein Pfeil und schneller Bogen,

Deines güldnen Rächers Pracht

Wird dem allen fürgezogen,

Was dich sonst berühmet macht.
APOLO

¿Así al dragón por fin

con el poder de mi arco

se calmó de salvaje venganza?

Ahora le rodea la noche,

el que antes la peste de la tierra era,

¿la vergüenza de los hombres?

Vosotros, pastores, traed los rebaños;

pues ya estáis fuera de peligro:

Vosotras, ninfas, trenzad coronas,

danzad bellos bailes laudatorios;

entrad intrépidas al bosque,

cantad hasta que los montes resuenen.

El animal nunca más ya

el aire envenenar podrá,

ni arrastrar enfermedad tras él.

Reanimad corazón y sentidos

Las mejillas nunca más habrán de empalidecerse,

se asemejarán a lilas y a rosas rojas;

pues el pitón ha sido matado

el que tormento os ha causado.

\section{CORO DE LOS PASTORES}

Gran dios, que paseas el carro de fuego alrededor de todo el bello cielo, tú que adornas el día, cada vez que amanece, con un manto dorado, que la clara luz traiga paz

a las noches tenebrosas;

que la luz del glaciar nos rodee,

Apolo, eso tú lo haces.

Que desde el hielo este gran círculo despoje

a la tierra

de su gris traje invernal,

Que praderas, campos y bosques renazcan,

Que las huestes aladas se muevan,

Que vuelen por los aires

y nos dediquen sus dulces cantos;

Que los árboles obtengan hojas,

¡Apolo, eso tú lo haces!

Tú, dios de las Artes, tú, cumplidor de

sueños,

Tú, príncipe de los juglares, tú, pelo ensortijado,

Tú, siempre joven, tú, montero mayor, todo lo tuyo es pleno;

pero tu flecha y arco veloz,

tu dorada grandeza de vengador

a todo aquello sobrepasa

que te hace por lo demás ser insigne. 
Wer kunt' ohn dich, o Phöbus, überwinden Das wilde Gift- und Flammenthier?

Komm, Cynthius, laß frische Kränze binden Um deiner gelben Haare Zier;

Laß die Blumen, so wir haben,

Dir, o Vater, lieber sein

Als der edlen Palmen Gaben

Und der Federn reichen Schein.
¿Quién podría sin ti, Febo, derrotar al feroz y venenoso animal incandescente? $\mathrm{Ea}$, Cintio, deja que frescas coronas trencen adornos en torno a tu rubia cabellera, deja que las flores que tenemos, te sean, oh Padre, más gratas que las dádivas de las palmeras y que el ostentoso brillo de las plumas. 


\section{AMORE}

Che tu vada cercando o giglio, o rosa per infiorarti i crini,

non ti vo' creder, no, madre vezzosa.

\section{VENERE}

Che cerco dunque o figlio?

\section{AMORE}

Rosa non già, né giglio.

Cerchi d'Adone, o d'altro vieppiù bello leggiadro pastorello

\section{VENERE}

Ah tristo, tristo! Ecco '1 signor di Delo; pe' boschi oggi se n' van gli dèi del cielo.

\section{APOLLO}

Dimmi possente arciero

qual fera attendi, o qual serpente al varco ch'hai la faretra, e l'arco?

\section{AMORE}

Se da quest' arco mio non fu Fitone ucciso, arcier non son però degno di riso e son del cielo Apollo un nume anch'io.

\section{APOLLO}

Sollo, ma quando scocchi l'arco, sbendi tu gl'occhi o ferisci all'oscuro arciero esperto?

\section{VENERE}

S'hai di saper desio d'un cieco arcier le prove chiedilo al re dell'onde chiedilo in cielo a Giove e tra l'ombre profonde del regno orrido oscuro chiedi, chiedi a Pluton s'ei fu sicuro?

\section{AMOR}

Que tú vayas buscando lirios o rosas para adornar con flores tu cabello no lo quiero creer, no, Madre agraciada.

\section{VENUS}

¿Entonces qué busco, hijo?

\section{AMOR}

Ni rosa, ni lirio:

buscas a Adonis, u otro aún más hermoso lindo pastorcito.

\section{VENUS}

¡Ah malvado! Ahí está el señor de Delos: hoy por los bosques van los Dioses del cielo.

\section{APOLO}

Dime, poderoso Arquero, ¿qué fiera esperas, o qué serpiente acechas, que tienes carcaj y arco?

\section{AMOR}

Aunque por este arco mío no fue muerto Pitón, sin embargo no soy arquero digno de risa y soy, Apolo, un numen del cielo yo también.

\section{APOLO}

Lo sé, pero cuándo disparas el arco, ¿te quitas las vendas de los ojos o hieres a ciegas, arquero experto?

\section{VENUS}

Si tienes el deseo de conocer las pruebas de un arquero ciego, pregúntaselo al Rey de las olas, pregúntaselo en el Cielo a Júpiter, y entre las sombras profundas del horrible Reino oscuro ipregunta, pregunta a Plutón, si él fue certero! 
DER ANDERE ACT

Cupido. Venus. Apollo.

CUPIDO

Was suchet ihr,

O Königin der schönen Frauen?

Wollt ihr nach Rosen schauen,

Nach Lilien zu eures Häuptes Zier?

Nein, liebste Mutter, nein.

VENUS

Was wird es dann wol sein,

Mein Kind, das mir gebricht?

CUPIDO

Wol Lilien noch Rosen nicht;

Adonis liegt euch in den Sinnen, und wo ein schöner Hirte funkt,

Die Ursach einer neuen Brunst,

Mag angetroffen werden können.

VENUS

Du kleiner Bösewicht!

CUPIDO

Seht ihr den Gott aus Delos nicht?

VENUS

Was wird hernach doch aus dem Himmel werden?

Gehn jetzt doch fast die Götter ganz auf

Erden.

APOLLO

Erzehle, du berühtmer Schütze,

Worzu sind die die Pfeil und Bogen nütze?

Ist ein grimmes Thier,

Das du meinest umzubringen,

Oder auch gedenkst du dir,

Einen Drachen zu bezwingen?

CUPIDO

Zwar Python ist durch meine Hand,

Apollo, nicht entleibet worden;

Jedennoch ist bekant,

Was ich für Thaten thu.

Ich bin so wol in deinem Orden,

Bin auch ein Gott wie du.

APOLLO

Das weiß ich wol; doch wann dein Bogen

Wird von dir abgezogen,

Machst du sehend andern Wunden

Oder triffst du auch verbunden?

VENUS

Im Fall du ja wilst wissen,

Apollo, was mein Sohn

Erwiesen hat im Schießen,

So höre nur hiervon,

Was neben uns Neptun im Wasser sage,

Und über uns der Jupiter;

Geh' unter uns zum Pluto hin und frage;Als

dann komm wieder her.

\section{ACTO SEGUNDO}

Cupido. Venus. Apolo.

CUPIDO

¿Qué buscáis, reina de las mujeres hermosas?

¿Queréis buscar rosas;

o lirios como ornamento de vuestra testa?

No, querida madre, no.

\section{VENUS}

¿Qué será esto, pues,

hijo mío, que me está haciendo padecer?

\section{CUPIDO}

$\mathrm{Ni}$ lirios ni rosas son por cierto,

es a Adonis a quien tenéis en mente,

$\mathrm{y}$ donde un apuesto pastor brilla,

el origen de un nuevo celo

se ha podido suscitar.

\section{VENUS}

¡Pequeño sinvergüenza!

\section{CUPIDO}

¿Acaso no veis al Dios de Delos?

VENUS

¿Y qué será del cielo después de esto?

Si ya los dioses casi siempre en la tierra moran.

APOLO

Cuenta, tirador afamado,

¿Para qué sirven flecha y arco?

Acaso para una bestia furiosa,

a la que piensas abatir,

o también estás planeando

a un dragón vencer?

\section{CUPIDO}

Si bien pitón por mi mano,

Apolo, no fue aniquilado;

de todos es conocida,

la envergadura de mis hazañas.

Pues estoy en tu misma orden, soy un dios al igual que tú.

\section{APOLO}

Ya lo sé; pero cuando el arco es tensado por ti mismo;

hieres a los otros con los ojos destapados

O también aciertas con los ojos vendados?

\section{VENUS}

En el caso de que quieras conocer,

Apolo, lo que mi hijo

ha evidenciado con los tiros,

solo has de escuchar,

lo que junto a nosotros Neptuno en el agua dice, y sobre nosotros Júpiter; desciende bajo nosotros a Pluto y pregunta; y después regresa aquí. 


\section{APOLLO}

$\mathrm{S}$ 'in cielo, in mare, in terra amor trionfi in guerra dove, dove m' ascondo chi novo ciel mi insegna, o novo mondo?

\section{AMORE}

So ben che non paventi

la forza d'un fanciullo

saettator di mostri, e di serpenti.

Ma prendi pur di me gioco, e trastullo.

\section{APOLLO}

Ah tu t'adiri a torto, o mi perdona Amore

$o$, se mi vuoi ferir risparmia ' 1 core.

\section{VENERE}

Vedrai che grave rischio è scherzar seco ben ch'ei sia pargoletto ignudo, e cieco.

\section{AMORE}

S'in quel superbo core non fo piaga mortale più tuo figlio non son, non son Amore.

\section{VENERE}

Amato pargoletto come giust'ira, e sdegno oggi t'infiamma il petto sì spero al nostro regno veder l'altero dio servo, e suggetto.

\section{AMORE}

Non avrò posa mai, non avrò pace fin ch'io no 'l vegga lagrimar ferito da quell' arco schernito madre ben mi dispiace di lasciarti soletta, ma toglie assai d'onor tarda vendetta.

\section{APOLO}

Si en el cielo, en el mar, en la tierra amor triunfas en la guerra ¿dónde, dónde me voy a esconder? ¿quién me va a mostrar un nuevo cielo, un nuevo mundo?

\section{AMOR}

Sé bien que no tienes miedo de la fuerza de un muchacho, tú que ensartas monstruos y serpientes; sin embargo puedes reírte de mí y bromear sin más.

\section{APOLO}

Ah tú te enfadas sin razón: o me perdonas, Amor, $o$, si quieres herirme, no me des en el corazón.

\section{VENUS}

Verás que riesgo entraña bromear con él, aunque él es niño, desnudo y ciego.

\section{AMOR}

Si en ese soberbio corazón no causo llaga mortal ya no soy hijo tuyo, no soy Amor.

\section{VENUS}

Querido niño, así como ira motivada e indignación hoy te incendian el corazón así espero en nuestro reino ver el dios altanero esclavo y atado.

\section{AMOR}

No tendré descanso, no tendré paz mientras no lo vea llorar herido por este arco despreciado. Madre, siento mucho dejarte sola, pero daña mucho el honor la venganza tardía. 
APOLLO

Weil Himmel, See und Erden

Und was darunter lebt,

Von dir gezwungen werden,

Weil nichts dir widerstrebt,

So zeige man mir doch noch einen Himmel an,

Noch einen Erdenkreis, in dem ich frei sein kann.

\section{CUPIDO}

Ich wuste wol, du würdest mich verlachen, Und daß ein Kind bei dir nichts gilt, Du großer Schütz und Tod der grimmen Drachen; halt mich für närrisch, wie du willst.

APOLLO

Erzürne dich so sehr nicht über mir, Cupido mein, o wende Gnade für; Wilt du mir ya mit deinem Bogen lohnen, So wollest du des Herzens doch verschonen.

VENUS

Du wirst wol sehn, was du gethan, Wann aus dem Scherzen Ernst entflehet, Wirst sehen, was mein Söhnlein kann, Wie wol es bloß und blind hergehet.

\section{CUPIDO}

Bring' ich dem stolzen Herzen

Nicht Angst und Todespein, so wil ich nicht dein Kind mehr sein.

VENUS

Du empfindest billich Schmerzen,

Eiferst billich, lieber Sohn.

Gib ihm seinen rechten Lohn,

Daß er möge noch erfahren,

Was deine Macht und seine Hoffart thu; Du wirst hier keiner Kräften sparen.

\section{CUPIDO}

Ich habe weder Kraft noch Ruh,

Bis ich mich recht an ihn gerochen

Und mit dem Bogen hier,

Den er vehöhnt zur Ungebühr,

Ihm seinen stolzen Muth gebrochen.

Gar gerne thu' ich's nicht, das ich sol von dir gehen;

Ich bleib' auch, wo mir's wird geschafft; Doch Rache, die man an leßt stehen, verliert durch Saumung ihre Kraft.
APOLO

Pues cielo, mar y tierra

y todo lo que en ellos mora

están sometidos a ti,

ya que nada se te resiste;

deseo por ello que se me muestre un cielo,

una parte de la tierra, en los que pueda ser libre.

\section{CUPIDO}

Ya sabía por cierto que te mofarías de mí, y que un infante no es nada para ti,

Tú, el gran protector y muerte del dragón furioso;

llámame loco, como tú quieras.

\section{APOLO}

No te sulfures tanto en mi contra; mi Cupido, apiádate de mi; si es que con tu arco premiarme quieres, del corazón deberías olvidarte.

\section{VENUS}

Comprobar podrás lo que has provocado; cuando la burla ahuyenta la seriedad; comprobar podrás, lo que mi querido hijo puede,

aún yendo y viniendo desnudo y ciego por ahí.

\section{CUPIDO}

Si al corazón altivo no le infundo miedo ni tomento mortal, no deseo seguir siendo tu infante.

\section{VENUS}

Pronto sientes el dolor, pronto el celo, querido hijo, dale pues lo que se merece, que aún pueda enterarse de lo que tu poder y su altanería pueden; no ahorrarás fuerzas en este empeño.

\section{CUPIDO}

No tendré fuerza ni paz hasta que de él me haya vengado y con este arco del que hasta la irreverencia tanto se burla, su altiva osadía haya quebrantado. Mas no lo hago a gusto, tener que separarme de tu lado así me quedo, donde se me ordena, mas la venganza que se deja detener, pierde por demora su poder. 


\section{VENERE}

Vanne pur lieto, o figlio lieta rimango anch'io, che troppo è gran periglio averti irato a canto per queste selve intanto farò dolce soggiorno; poscia faremo insieme al ciel ritorno.

Chi da' lacci d'Amor vive disciolto

della sua libertà goda pur lieto, superbo no' d'oscura nube involto

stassi per noi del ciel l'alto decreto;

s'or non senti d'Amor poco né molto, avrai dimani il cor turbato, e 'nqueto,

e signor proverai crudo, e severo Amor, che dianzi disprezzasti altero.

\section{CORO}

Nudo arcier, che l'arco tendi, che velat' ambe le ciglia ammirabil meraviglia, mortalmente i cori offendi se così t'infiammi, e 'ncendi verso un dio, quai saran poi sovra noi gli sdegni tuoi? D'un leggiadro giovinetto già de' boschi onore, e gloria suona ancor fresca memoria che m'agghiaccia ' 1 cor ne ' 1 petto, qual per entro un ruscelletto sé mirando, arse d'amore, e tornò piangendo in fiore. Ogni ninfa, in doglie e ' $n$ pianti posto avea per sua bellezza, ma del cor l'aspra durezza non piegar l'afflitte amanti; quelle voci, e quei sembianti ch'avrian mosso un cor di fera, schernia pur quell' alma altera.

\section{VENUS}

Sin embargo vete contento, hijo; yo también me quedo contenta, porque es demasiado grande el peligro de tenerte cerca cuando estás airado: mientras por estas selvas disfrutaré de una agradable estancia; después volveremos juntos al Cielo.

Quien vive sin las ataduras de los lazos de amor,

goce de su libertad contento sí, pero no soberbio: envuelto en una nube oscura

se encuentra para nosotros el alto decreto del Cielo:

si ahora no sientes ni poco ni mucho amor mañana tendrás en corazón perturbado e inquieto, y experimentarás que amo cruel y severo es Amor, que antes despreciaste altivo.

\section{CORO}

Arquero desnudo, que el arco tensas, que, entrecerrando las pestañas, ¡admirable maravilla!

mortalmente hieres los corazones.

$\mathrm{Si}$ así te enciendes e inflamas contra un Dios, ¿cuál puede ser entonces contra nosotros tu indignación?

De un lindo jovencito, que fue honor y gloria de los bosques, suena todavía fresca la memoria, que me hiela el corazón en el pecho, de cómo dentro de un riachuelo mirándose a sí mismo ardió de amor y llorando se volvió flor.

Con su belleza había arrastrado a todas las ninfas al dolor y el llanto, pero la rígida dureza de su corazón no doblegaron las afligidas amantes: esas voces y esos rasgos, que emocionarían el corazón de una fiera, esa alma altiva sin embargo escarnecía. 


\section{VENUS}

Geh immer hin in Zeiten

Und denk ans Rach' und Gift;

Dann wann du zornig bist,

So hat man ohne Gefahr dich nicht an seiner Seiten.

Ich kann allhier indessen bleiben

Und um den grünen Wald

Die Zeit vertreiben;

hernach, so bald

Du herkömst, wil ich mit dir hin

In unfern Himmel ziehn.

Wer von der Lieb ist krank und frei, der mag wol fröhlich leben,

Doch schau' er zu, daß er nicht sei

Der Hoffart allzusehr ergeben;

Er laß uns unverlacht.

Diß ist der Schluß, den hat mein Sohn gemacht,

Der Abschied, den er spricht.

Fühlt ihr gleich Lieb' anjetzund nicht,

So kan doch bald ein Stündlein kommen,

In dem durch ihre Pein

Euch Muth und Herze wird benommen.

Alsdann wird Amors Macht

Euch nicht verborgen sein,

Die ihr anjetzt verlacht.

\section{CHOR DER HIRTEN}

O du kleiner nackter Schütze ,

Wann der Bogen, den du spannst,

Giebet solche Liebeshitze

Daß du Götter fellen kanst,

Was dann wirst du nicht, o Kind,

Uns thun, die wir Menschen sind?

Unser Herze muß sich krenken,

Unsere Sinnen sind betrübt,

Wann wir an den Jüngling denken,

Der sich in sich selbst verliebt,

Der verlor die Menschenart,

Und zu einer Blumen ward.

Aller schönen Nymphen Herzen

Branten gegen ihm für Pein;

Aber er ließ ihre Schmerzen

Ohne Trost und Hoffnung sein.

Zwar sehr groß war seine Zier,

Doch der Hochmuth gieng ihr für.

\section{VENUS}

A tiempo siempre llega

y piensa en venganza y veneno;

pues cuando tú enfureces,

no se puede sin peligro estar a tu lado.

Yo mientras aquí puedo morar

y por el verde bosque

el tiempo dejaré pasar;

después, cuando regreses,

contigo quiero partir

y al cercano cielo ir.

El que enfermo de amor sea libre, ese podrá vivir feliz,

mas ha de vigilar no entregarse

en demasía a la altanería;

nos dejará sin burlas.

Este es el final que mi hijo ha causado,

la despedida, al que habla.

Si quizás no sentís amor aún;

podrá acercarse pronto el momento

en el que su tormento

os robe vuestro coraje y corazón.

Será entonces cuando el poder de Amor no se os oculte más;

del que tanto ahora os mofáis.

\section{CORO DE LOS PASTORES}

Pequeño y desnudo tirador, si el arco que tú tensas, tal fuego de amor enciende que hace caer a los dioses, ¿qué no nos harás, niño, a nosotros, los que hombres somos?

Nuestro corazón enferma, nuestros sentidos están desolados, cuando en el joven pensamos, que se enamoró de sí mismo, el que perdió su humana condición y en una flor se transformó.

Los corazones de las bellas ninfas todas ardían atormentadas por él;

Mas él sus sufrimientos dejó sin consuelo ni esperanza.

Era grande su hermosura, mas la arrogancia la aventajó. 
Una al pianto in abbandono lagrimando uscì di vita, che fu poi per gl' antri udita rimbombar nud'ombra, e suono; or qui più non ha perdono, più non soffre Amore irato l'impietà del core ingrato. Punto ' 1 sen di piaga acerba da quell'armi, ond'altri ancise, non pria fine al pianto ei mise ch'un bel fior si fe' su l'erba;

o beltà cruda e superba non fia già, ch'invan m'insegni come irato Amor si sdegni.

\section{DAFNE}

Del fugitivo cervo quest'è pur orma impressa fusse almen qui vicin la fera stessa.

\section{APOLLO}

Qual d'un bel ciglio adorno spira lume gentil, ch'al cor mi giunge?

\section{DAFNE}

Certo non molto lunge se 'l desir non m'inganna è qui d'intorno or vedrò se 'l mio stral va dritto, e punge.

\section{APOLLO}

Ah ben sent'io se son pungenti i dardi de' tuoi soavi sguardi; dimmi qual tu ti sei o ninfa, o dèa che tale rassembri agl'occhi miei che cerchi armata di faretra, e strale?

\section{DAFNE}

Seguendo io me ne giva per quest'ombrosa selva i passi e l'orme di fugace belva, e son donna mortal non del ciel diva.
Una abandonándose al llanto y vertiendo lágrimas salió de la vida y después los demás la oyeron retumbar como sombra desnuda y sonido: ahora aquí ya no tiene perdón, ya no sufre Amor airado la crueldad del corazón desagradecido. Con el pecho zaherido por una llaga cruel de ese arma que mató a otros, no dio fin al llanto antes de que se trasformara en una hermosa flor en la hierba.

Belleza cruel y soberbia, no pase nunca que en vano me muestres como Amor airado se indigne.

\section{DAFNE}

Del ciervo fugitivo esta es sin embargo la huella estampada: ¡Si por lo menos estuviera aquí cerca también la fiera!

\section{APOLO}

¿Qué luz agraciada adornada de hermosas pestañas

Irradia y me llega al corazón?

\section{DAFNE}

Seguro que no muy lejos, si el deseo no me engaña, está en los alrededores:

ahora veré si mi flecha va derecha y se clava.

\section{APOLO}

¡Ah, yo noto bien si se clavan las flechas de tus dulces miradas!

Dime lo que tú eres ¿ninfa o Diosa, que tal pareces a mis ojos? ¿Qué buscas armada de carcaj y flecha?

\section{DAFNE}

Yo iba siguiendo por esta selva sombría los pasos y las huellas de una bestia fugitiva y soy mujer mortal, no diosa del Cielo. 
Eine starb im Liebesorden, Gar zu tief durch ihn versehrt, Die hernach ein Schall ist worden, den man nach uns rufen hört: Aber Amors grimme Macht Strafte solche strenge Pracht. Wie er sonst hat euch versehret, $\mathrm{O}$ ihr Nymphen, für der Zeit,

Also ward er jetzt bethöret Durch sein'eigne Zierlichkeit, Biß er noch sein Ende nahm, und in Zahl der Kräuter kam. Laßt uns ja uns selbst nicht lieben,

Bild'ihn niemand zu viel ein, Wil er sich nicht selbst betrüben und in Furcht ohn Hoffnung sein; Wünsch 'ihm weder Weib noch Mann, $\mathrm{Zu}$ erfahrn, was Amor kan.

DER DRITTE ACT.

DAFNE. APOLO.

\section{DAFNE}

Es ist die Spur des Hirschen ja für mir; Wie laß bin ich! Ach! wer' er doch allhier.

\section{APOLLO}

Wer muß nur diese sein, Die aus den Augen lesset blinken So einen hellen Himmelschein, den ich spür in mein Herze sinken?

\section{DAFNE}

Ich denk' ihm wol für zu biegen Im Fall ich eile.

Ich muß nur sehn, ob auch der Pfeil wird fliegen

Und scharf sein, wie er sol.

APOLLO

Ach! Scharf genug sind deiner Augen

Pfeile;

Ich fühle sie ja wol!

Sie verwunden mich von fernen.

Bist du nicht der Nymphen eine,

Oder, wie ich auch vermeine,

eine Göttin aus den Sternen?

Wie, daß du Pfeil'und Bogen an dich henkest?

DAFNE

Ich suche in schnelles Wild Und bin ein steblichs Weibesbild, Nicht eine Göttin wie du denkest.
Una murió de amor,

por él en exceso herida,

y se transformó en un son

al que se escucha llamarnos:

mas el poder terrible de Amor

esa austera pompa castigó.

Como a vosotras os había herido, ninfas, con anterioridad,

él mismo se destruyó

por su propia gracilidad,

hasta que su final encontró

y entre las hierbas habita.

No dejéis que nos amemos a nosotros mismos,

que nadie demasiado se envanezca, si no desea a sí mismo afligirse y hallarse atemorizado y sin esperanza; ni a mujer ni a hombre le desearía experimentar de lo que es capaz Amor.

ACTO TERCERO

DAFNE. APOLO.

\section{DAFNE}

La huella del ciervo es para mí; ¡Cuán negligente soy!¡Ay, si él estuviera por aquí!

\section{APOLO}

¿Quién ha de ser ella, que hace brillar de sus ojos tal claro y celestial resplandor, que siento atravesar mi corazón?

\section{DAFNE}

Creo que quizás lo doble si con prisas voy.

Solo he de ver que la flecha vuele

y esté afilada, como debe.

\section{APOLO}

¡Ay, bien afiladas están las flechas de tus ojos;

yo las siento así!

Desde lejos ya me hieren.

Eres una entre las ninfas acaso, o, como también sospecho; ¿una diosa de las estrellas? ¿Cómo es que de ti penden flecha y arco?

\section{DAFNE}

Voy en pos de un veloz venado Y soy una mortal figura de mujer, no una diosa como crees. 


\section{APOLLO}

Se cotal luce splende

in bellezza mortale

del ciel più non mi cale.

DAFNE

Dove mi volgo dove

moverò 'l passo, che la fera trove?

\section{APOLLO}

Senza che dardo avventi, o l'arco scocchi valli cercando, o monti

far nobil preda puoi co' tuoi begl'occhi.

\section{DAFNE}

Altra preda non bramo, altro diletto che fere, e selve, e son contenta e lieta

se damma errante o fer cignal saetto.

APOLLO

Ah che non sol di fere

saettatrice sei

ma contro a gl'alti iddèi

saette avventi da le luci altere.

\section{DAFNE}

Del ciel gl'eterni numi

umile onoro e colo,

e per le selve solo

pongo su l'arco i dardi:

ma tu per gioco il mio cammin ritardi.

\section{APOLLO}

Deh non sdegnar che teco

compagno venga, anch'io so tender l'arco

e quando non ti spiaccia

farem daccordo dilettosa caccia.

DAFNE

Altri che l'arco mio non vo', compagno addio.

\section{APOLO}

Si una luz parecida resplandece en una belleza mortal, ya no me importa del Cielo.

DAFNE

¿Dónde me dirijo? ¿adónde voy a mover el paso para encontrar la fiera?

APOLO

Sin que dispares un dardo o tenses el arco, buscando valles o montes, puedes cazar una noble presa con tus bellos ojos.

\section{DAFNE}

No deseo otra presa, otro deleite más que fieras y selvas, y estoy contenta y alegre

si gamo errante o fiero jabalí ensarto.

\section{APOLO}

Ah que no sueles solo ensartar

las fieras

sino que contra los sumos dioses

lanzas flechas de las luces altivas

\section{DAFNE}

Los eternos númenes del Cielo humilde honro y venero, y por las selvas solo pongo en el arco las saetas: pero tú por una broma retrasas mi camino.

\section{APOLO}

Ah no desprecies el hecho de que contigo vaya como compañero: yo también sé tensar el arco, y cuando no te disguste iremos juntos de caza placenteramente.

\section{DAFNE}

Otro que no sea mi arco no quiero como compañero: adiós 
APOLLO

Glänzt in der schönen Sterblichkeit dergleichen Licht,

So frag ich nach dem Himmel nicht.

DAFNE

Das Thier verläuft sich allzuweit; Ich muß den Fuß nur ferner setzen.

APOLLO

Du kanst doch mit den Augen hetzen, Im FAll du schon nicht Berg und Thal Mit deinen Pfeilen

Durchsuchest überall.

DAFNE

Nichts anders such ich zu ereilen, Die Lust, so ich im Sinne führe, Sind Berge, Pfüsch' und Thiere; Dies ist der Raub, der bei mir gilt.

APOLLO

Du sollest nicht nur bloßes Wild; Dann deiner stolzen Augen Licht kan auch die Götter selbst versehren; Ihr Herz ist für dir sicher nicht.

\section{DAFNE}

Die Götter pfleg' ich hoch zu ehren; Durch meine Pfeil und Bogen Wird nur das Wild betrogen. Du aber säumest mich Mit langem Stehen.

\section{APOLLO}

Vergönne mir, daß ich

Mag mit dir gehen.

Ich weiß die Thiere wol zu fellen:

Wir wollen eine Jagt

Mit großer Lust anstellen, die mir und dir behagt.

\section{DAFNE}

Es darf sich nichts zu mir gefellen Als Pfeil und Bogen nur. Glück zu!
APOLO

Si en la bella mortalidad tal resplandor brilla, no deseo buscar el cielo.

\section{DAFNE}

Muy allá extravióse el animal; más lejos he de posar mi pie.

APOLO

Con tus ojos puedes acosar, si por montes y valles con tus flechas no has rebuscado todo ya.

\section{DAFNE}

Ninguna otra cosa busco alcanzar, el placer con el que deleito mis sentidos, son los montes, abustos y animales; estas son las presas que pretendo hacer.

\section{APOLO}

No solo simple venado debías perseguir; pues la altiva luz de tus ojos también a los mismos dioses puede herir, su corazón no está seguro ante ti.

\section{DAFNE}

A los dioses suelo ofrecer altos honores; con mi flecha y arco solo al venado engaño. Pero me estás reteniendo mucho tiempo en pie.

\section{APOLO}

Te ruego me complazcas y me permitas contigo ir. Pues sé alcanzar bien a los animales: abriremos la veda con una gran pasión que a mí y a ti agradará.

\section{DAFNE}

Nada más puede acompañarme, sólo flecha y arco.¡Buena suerte! 
APOLLO

Ohimè non tanta fretta aspetta ninfa, aspetta.
APOLO

¡Ay de mí! Sin tanta prisa espera, Ninfa, espera. 
APOLLO

Ach, warte! Warum eilest du?

Erkenne doch, o Schöne, wer dich liebet;

Ein Gott ists, der sich dir ergibet,

Der dich begehrt; gib deinem Glücke statt,

Nim an den guten Rath.

Ach fleuch, ach fleuch doch nicht!

Mein Herze, das zerbricht

Und zwingt mich, daß ich schneller eile

Als diese meine Pfeile,

Wann mir ein Wild aufstößt.

Du rennest, läufst und gehst,

Wohin du willst, so wil ich folgen können.

Wer eifrig liebt, dem kan kein Ding entrinnen.

\section{CHOR DER HIRTEN}

Liebe, wer sich selber haßt; Aber wer sein gutes Leben Wil der freien Ruh ergeben, Reißt sich von der argen Last,

Suchet für das süße Leiden Felder, Wild, Gepüsch und Heiden. Ihm gefällt die Faulheit nicht, Die nicht als zum Bösen machet, Die den Trägen schwächer machet, Und der starken Kraft zerbricht, Die den Geist zeucht auf die Erden Und heißt Männer Kinder werden. Seine Lust, die er begehrt, Die ihm kürzet manche Stunde, Sind berühmte schöne Hunde Und ein ritterliches Pferd; Sein Gemüthe muß sich leßen Mit dem adelichen Hetzen. Wann der Reis das Feld bethaut Und die Vögel mit dem Singen Um die Morgenröthe springen, Sitzt er munter auf und schaut, Ob er mit den schnellen Winden kan ein großes Stücke finden. Also bringt die scharfe Pein Nimmer in sein großes Herze, Das von Wollust, Lieb'und Scherze Ganz wil frei und sicher sein, Wil nicht von den Freuden wissen, Die Gemüth' und Leib muß büßen; Flieht ingleichen diese Lust, Die doch nur den weichen Sinnen, So nichts Mannlichs üben können, Sol bekant sein und bewußt, Die nur wie ein Schatten stehet, Der bald wird und bald vergehet.

\section{APOLO}

¡Ay, espera!¿Por qué te apresuras?

Reconoce, bella, a quien te ama; Es un dios, el que se te entrega y te desea, satisface tu suerte, acepta el buen consejo.

Y, ¡ay, no huyas, pero no huyas!

Mi corazón se quiebra

y me hace correr más rápido

que mis propias flechas cuando un venado me embiste.

Ya puedes volar, correr o andar hacia donde quieras, yo te seguiré.

Al que ama con pasión, nada se le puede escapar.

\section{CORO DE LOS PASTORES}

Amor, el que a sí mismo se odia;

Mas el que su buena vida

a la libre paz desea entregar;

se libera de la gavosa carga,

y que busque para su dulce padecer campos, venados, arbustos y praderas.

La pereza a él no le agrada, pues sólo guía hacia el mal y a los holgazanes debilita y quiebra la firme fuerza, que demuestra el espíritu en la tierra y hace a los hombres llamarse niños. Su pasión, la que él ansía, la que acorta algunas de sus horas, son los célebres y bellos canes

Y un caballeresco corcel;

Su ánimo ha de ser alterado con el noble agravio.

Cuando el arroz se siembra en los campos y los pájaros con sus cantos al alba revolotean, se sienta con brío y contempla, si con los veloces vientos puede encontrar una buena pieza. Por eso el agudo tormento nunca penetra en su gran corazón, que de lujuria, amor y chanzas mantenerse alejado quiere y ser libre, ni conocer las alegrías desea que alma y cuerpo han de expiar. Huye igualmente esta pasión, que solo los débiles sentidos, y así nada viril pueden ejercitar, conocen y son conscientes, que sólo como una sombra flota, que pronto aparece y pronto se esfuma. 


\section{AMORE}

Ve' che ti giunsi al varco;

o' impara a disprezzar l'etate, e l'arco.

Orsù dell' alto cielo

mirin gl'eterni dèi

le glorie, e vanti miei

e voi quaggiù mortali

celebrate il valor de' gl'aurei strali.

\section{VENERE}

Figlio, dolce diletto

del cor degl'occhi miei

come sì lieto, e baldanzoso sei?

Dillo bel pargoletto

dimmelo Amor, ch'anch'io

senta le gioie tue dentr'al cor mio.

\section{AMORE}

Madre, di gemme, e d'oro

un bel carro m'appresta;

pommi su l'aurea testa

nobil fregio d'onor, cerchio frondoso;

veggammi oggi gli dèi dell'alto cielo

trionfator pomposo,

quel dio, ch'intorno gira

il carro luminoso

vinto dall' arco mio piange, e sospira.

\section{VENERE}

Qual degl'iddei del cielo

de' la faretra invitta

non sentì dentr'al cor pungente telo?

Io che madre ti sono, ahi quanto, ahi quanto il molle sen trafitta

e ' $n$ cielo, e ' $n$ terra ho lagrimato e pianto.

\section{AMORE}

S'hai lagrimato, e pianto, hai riso ancora

dimmi piangevi allora

che del fabro geloso

non potesti schivar l'inganno ascoso?

\section{AMOR}

Ves que al acecho te alcancé:

aprende qué cosa es despreciar la edad y el arco.

Ahora miren los eternos Dioses

del alto Cielo

mis glorias y mis honores;

y vosotros los mortales aquí abajo

celebrad el valor de las saetas áureas.

\section{VENUS}

Hijo, dulce deleite

del corazón, de mis ojos

¿cómo estás tan alegre e intrépido?

dilo, niño hermoso,

dímelo, Amor, que yo también

sienta tus alegrías en mi corazón.

\section{AMOR}

Madre, de joyas y oro

prepárame un hermoso carro;

ponme en la áurea cabeza

un noble lazo de honor, círculo frondoso;

que los Dioses del alto Cielo me vean

triunfador solemne.

Ese Dios, que hace girar alrededor

el carro luminoso

vencido por el arco llora y suspira.

\section{VENUS}

¿Cuál de los Dioses del Cielo

del carcaj invicto

no sintió en el corazón la flecha

puntiaguda?

Yo, que soy tu madre, ¡ay cuánto, ay cuánto con el blando pecho atravesado

en el cielo y en la tierra derramé lágrimas y

lloré!

\section{AMOR}

Si derramaste lágrimas y lloraste, también te reiste.

Dime, ¿llorabas cuando

del Herrero celoso

no pudiste esquivar el engaño oculto? 


\section{DER VIERTE ACT.}

CUPIDO. VENUS.

\section{CUPIDO}

Was gilt's? Ich habe dir den stolzen Muth gebrochen,

Der meine Macht

Sonst hat verlacht,

Und mich an dir gerochen!

So lernt ihr Götter nach der Zeit

hier meines Röchers innen werden;

Und ihr, ihr Sterblichen, erhebet weit und breit

Mein hohes Lob auf Erden.

\section{VENUS}

O süßer Sohn, was hastu doch gethan? Was wil diß Fröhlichsein und Lachen? Was ist es doch, mein Kind? Sag an, $\mathrm{Da} ß$ ich mich auch kan lustig machen.

\section{CUPIDO}

O Mutter, laß mir einen Wagen Von Gold und edlen Steinen bauen. Jetzt mag ich einen Kranz zum Siegeszeichen tragen;

Die Götter sollen heute schauen, Wie recht ich triumphieren kan, Der Gott, so von der Himmelsbahn mit seiner Strahlen Kraft die ganze Welt durchscheint,

hat meines Bogens Rach' empfunden, Geht jetzt und weint,

Ist krank an Liebeswunden.

\section{VENUS}

Kan ein Gott auch rühmen sich, $\mathrm{Da}$ er für dir frei sei bleiben? Sohn, Sohn, denke wer bin ich! Folgt doch deine Mutter dir, Muß nach deinem Willen lieben, Götter oben, Menschen hier.

\section{CUPIDO}

Zwar traurig hab ich dich gemacht, Jedoch so hastdu auch gelacht. Ich habe dich gar nie gesehen weinen, Wie Mars in deinen Armen lag, Eh' als der helle Tag Verrähtrisch ließ die Strahlen auf euch scheinen.

\section{ACTO CUARTO}

CUPIDO. VENUS.

\section{CUPIDO}

¿Qué vale? Quebranté tu altiva osadía que de mi poder hasta entonces se burló, iy de ti me he vengado! Así vosotros dioses aprendéis a verme aquí como vengador; $\mathrm{Y}$ vosotros, los mortales; elevad por doquier mi alabanza suprema por la tierra.

\section{VENUS}

Dulce hijo, ¿qué es lo que has hecho? ¿Qué me dicen tus risas y felicidad? ¿Pero qué es, mi niño? Confiesa para que yo también me pueda divertir.

\section{CUPIDO}

Madre, déjame un carro construir de oro y piedras preciosas.

Ahora portaré una corona como símbolo de victoria;

hoy los dioses deben ver cuán triunfante puedo ser.

El dios que desde su órbita con su fuerza resplandeciente toda la tierra ilumina, ha sentido de mi arco la venganza, se ha ido y llora herido de amor.

\section{VENUS}

¿Puede un dios vanagloriarse de permanecer libre para ti? Hijo, hijo, piensa quién soy yo, si tu madre te siguiera según tu voluntad amar debiera, los dioses arriba, los hombres aquí.

\section{CUPIDO}

Si bien te he entristecido; también has reído, nunca te vi llorar, cuando Marte en tus brazos yacía antes de que el claro día dejara caer sus rayos sobre vosotros con alevosía. 


\section{VENERE}

Taci taci bel figlio,

pur troppo e tu lo sai

il mio bel viso allor si fe' vermiglio;

ma di tornare al ciel è tempo ormai.

\section{CORO}

Non si nasconde in selva

sì dispietata belva,

né su per l'alto polo

spiega le penne a volo, augel solingo

né per le piagge ombrose,

tra le fere squamose alberga core

che non senta d'amore.

Arder miriam le piante

l'una dell'altra amante,

e gl'elementi ancora

bel foco arde e innamora, e insieme accora

sol contro gl'aurei strali,

i semplici mortali armano il core

che non senta d'amore.

Questi l'albe, e le sere

perde cacciando fere,

e quei s'al ciel rimbomba

di Marte altera tromba, all' armi corre;

altri la mente vaga

di mortal fasto appaga, e 'ndura il core,

che non senta d'amore.

Ma se d'un ciglio adorno

mira le fiamme un giorno;

o pregio d'un bel volto

scherzar con l'aure sciolto un capel d'oro

già vinto ogn' altro affetto;

prova, ch' in uman petto non è core

che non senta d'amore.

\section{VENUS}

Calla, calla, hijo hermoso

por desgracia, y tú lo sabes,

mi hermoso rostro entonces se puso

colorado

pero ya es hora de volver al Cielo.

\section{CORO}

En la selva no se esconde

bestia tan despiadada,

ni arriba por el polo alto

despliega las plumas en vuelo pájaro

solitario,

ni por las playas en sombras

entre las fieras escamosas se cobija un

corazón

que no sienta algo de amor.

Miramos las plantas arder

amándose una a otra,

y también los elementos

fuego hermoso quema y enamora, y juntos

empareja:

contra las flechas áureas solo

los simples mortales arman el corazón

para que no sienta amor.

Este albas y noches

pierde cazando fieras,

y ese, si en el Cielo retumba

la altiva trompeta de Marte, corre a coger

las armas;

otro la mente anhelante

apacigua con fasto mortal y endurece el

corazón

para que no sienta amor.

Pero si un día mira las llamas

de hermosas pestañas

o el valor de un hermoso rostro

bromear con el aire, con el cabello de oro

suelto,

ya derrotado cualquier otro sentimiento prueba que en el pecho humano no existe corazón

que no sienta amor 


\section{VENUS}

Ach schweig! Doch weißest du, wie mir entfiel der Muth,

Und wie mein Anlitz ward als Blut.

Aber laß uns hier nicht stehen;

Es ist Zeit,

heim zu gehen

In das Haus der Ewigkeit.

\section{CHOR DER HIRTEN}

Kein schnelles Wild, das in den Büschen lebt,

Dem Gras die Nahrung gibt,

Kein Vogel auch, der um die Wolken

schwebt,

kein Fisch bleibt unverliebt;

Nichts ist, was wohnt auf Erden,

Was Luft und See durchstreicht,

Was ist und noch sol werden,

Das nicht der Liebe weicht.

Die Kräuter selbst, so ohne Geist aufgehn,

Sind Freund doch unter sich;

Kein Element kan bei dem andern stehn,

O Amor, als durch dich.

Der Mensch ist's der die Gaben

Des Liebens von sich streicht

Und wil ein Herze haben,

Das nicht der Liebe weicht.

Der eine stellt auf ungezähmtes Wild,

Der reiset Tag und Nacht,

Ein andrer hört, wann die Trompet'

erschüllt

und Fug zum Kriegen macht;

Der schauet, daß mit Scherze

Und Lust die Zeit verstreicht,

Damit er hat ein Herze,

das nicht der Liebe weicht.

Doch wann uns kömt des Leibes theure

Waar,

Der Augen Strahlen für,

der weiße Hals, das goldgemengte Haar

der rothen Lippen Zier,

So muß man innen werden,

$\mathrm{Da}$ nichts sich ihnen gleicht

Und kein Ding sei auf Erden,

Das nicht der Liebe weicht.

\section{VENUS}

¡Ay, calla! Sabes bien cómo mi valor decayó,

y cómo mi rostro como sangre se tornó, pero no permanezcamos aquí.

Es tiempo de regresar a casa;

a la casa de la eternidad.

\section{CORO DE LOS PASTORES}

No hay venado alguno, cuales viven entre arbustos,

al que la hierba alimenta,

ni pájaro tampoco, cuales flotan por las

nubes,

ni pez siquiera que no sea amado.

Nada hay que viva en la tierra,

que recorra aire y mar;

que ya sea o que vaya a ser,

que no ceda al amor.

Ya sean las hierbas, que aún sin espíritu

brotan,

entre ellas se amigan;

no hay elemento, que junto a otro permanecer

pueda,

Amor, si no fuera por ti.

Es el hombre quien los dones

del amor lanza lejos de sí,

y un corazón desea poseer

que al amor no ceda.

Uno se enfrenta a un venado salvaje;

y viaja día y noche,

el otro escucha cuando suena la trompeta

y encuentra la ocasión para obtener algo:

y contempla, cómo con chanzas,

y alegría el tiempo pasa,

Y así un corazón obtiene,

que al amor no obedece.

Mas cuando surge el caro afán del cuerpo,

los rayos que de los ojos brotan,

el blanco cuello, los cabellos entrelazados con oro,

el adorno de los labios encarnados,

hemos de aceptar

que nada hay igual

Y que no hay materia en la tierra

que al amor no ceda. 


\section{NUNZIO}

Qual nova meraviglia

veduto han gl'occhi miei?

O sempiterni dèi,

che per lo cielo volgete

nostre sorte mortali, o triste, o liete,

fu castigo, o pietate cangiar l'alma beltate?

\section{CORO}

Pastor deh narra a noi

le nove meraviglie,

che visto han gl'occhi tuoi.

\section{NUNZIO}

Non senza trar dal core

lagrime di dolore

udirete, pastori,

il destin della bella cacciatrice

pur troppo miserabile, e infelice.

CORO

Di' pur, saggio pastore,

che non senza dolore

lagrima per pietate un gentil core.

\section{NUNZIO}

Quando la bella ninfa

sprezzando i prieghi del celeste amante

vidi che per fuggir movea le piante,

da voi mi tolsi anch'io

l'orme seguendo dell' acceso dio.

Ella quasi cervetta

ch'innanzi a crudo veltro il passo affretta

fuggia veloce, e spesso

si volgeva a mirar se lungi, o presso

avea l'odiato amante,

ma fatt' accorta omai,

ch'era ogni fuga invano,

i lagrimosi rai

al ciel rivolse, e l'una, e l'altra mano,

e 'n lamentevol suono,

ch'io non udii che troppo era lontano

sciolse la lingua: ed ecco in un momento

che l'uno, e l'altro leggiadretto piede

che pur dianzi al fuggir parve aura, o vento

fatto immobil si vede

di selvatica scorza insieme avvinto,

e le braccia, e le palme al ciel distese,

veste selvaggia fronde;

\section{MENSAJERO}

¿Qué nueva maravilla

han visto mis ojos?

Dioses sempiternos,

que en el Cielo tornáis

nuestros destinos mortales o tristes o

alegres,

¿fue castigo o piedad

cambiar la magnífica belleza?

CORO

Pastor, ah, cuéntanos

las nuevas maravillas

que han visto tus ojos.

\section{MENSAJERO}

No sin extraer del corazón

lágrimas de dolor

vais a oír, Pastores,

el destino de la hermosa cazadora

por desgracia miserable y desgraciado.

CORO

Habla habla, sabio Pastor,

que no sin dolor

llora por piedad un noble corazón.

\section{MENSAJERO}

Cuando a la hermosa Ninfa,

despreciando los ruegos del amante celeste, vi que para huir movía las plantas,

yo también me alejé de vosotros, siguiendo las huellas del Dios encendido. Ella, casi como una joven cierva que ante un cruel galgo apresura el paso, huía rauda, y a menudo se daba la vuelta, mirando si lejos o cerca tenía al odiado amante;

pero, percibiendo ya

que cualquier huida era vana,

los ojos llorosos

dirigió hacia el cielo, y una y otra mano,

y un sonido lastimero,

que yo no oí, porque estaba demasiado

lejos,

desató la lengua: y he aquí que un

momento,

cada uno de los lindos pies

que sin embargo antes durante la huida

pareció aire o viento,

se ve quedarse inmóvil

por corteza silvestre rodeado,

y los brazos y las palmas extendidas hacia

el Cielo

viste silvestre fronda. 


\section{DER FÜNFTE ACT.}

APOLLO. DAFNE

APOLLO

Bleib, Nymphe, bleib; ich bin dein Feind ja nicht,

$\mathrm{Da}$ du so läufst, mein Licht,

Als wann ein armes Schaf vom Wolfe wird getrieben.

Mein Folgen kömt vom Lieben.

Ach, ach, daß für die große Brunst

kein Kraut wächst auf de Erden!

Was hilft mich jetzo meine Kunst,

Durch welche sunst

Ein jeder heil kan werden.

DAFNE

O Vater Peneus, nim mich an,

Dein unbeflecktes Kind! O Vater, hilf doch mir,

Im Fall ein Fluß auch helfen kan.

Bedeck', o Erde, mich; nim zu dir meine

Zier,

Verschling sie, oder laß sich meinen Leib

verkehren

In etwas, welches mich kan der Gewalt erwehren.

\section{APOLLO}

Sol dann, ihr harten Rinden,

Die unbefleckte Zier,

So Herz und Sinn mir kunte binden,

In euch verdeeckt sein für und für?

Ihr Augen, die ihr mehr ein Duell als Augen seid,

Bleibt an die Zweige hier geheftet jederzeit.

Hier, da ist das edle Herze,

So das meine mir zerbricht,

Hier ist meiner Sonnen Licht,

Das die helle Tageskerze,

Die Vertreiberin der Nacht,

Aller schwarz und tunkel macht.

Wiewol ich sonst unsterblich bin,

Doch sterb' ich ihrentwegen hin.

Ach Nympfe, die du dich

hast eines Gottes Lieb' erwehret,

Dadurch dein schöner Leichnam sich

In einem Lorbeerbaum verkehret,

Es wiederfahr' in Ewigkeit ya nicht,

$\mathrm{Da}$ ich dein Lob nicht soll' in Himmel mit dir führen.

Mit den Blättern wil ich allzeit, o mein Licht, Diß güldne Haar mir zieren.

\section{ACTO QUINTO}

APOLO. DAFNE

\section{APOLO}

Espera, ninfa, espera, pues no soy tu enemigo

para que de este modo corras, lucero mío; como la pobre oveja empujada por el lobo.

Pues por amor te sigo.

Ay, ay, que para el gran celo no crece hierba sobre la tierra, para qué mi arte ahora me sirve con el que hasta ahora todos pueden sanar.

\section{DAFNE}

Padre Peneus, acógeme,

a tu hija inmaculada, ayúdame, te lo ruego,

si es que un río aún puede ayudar.

Cúbreme, tierra, toma para ti mi hermosura,

devórala, o bien haz que mi cuerpo se transforme

en algo que de la violencia pueda defenderse.

\section{APOLO}

Debe entonces, vosotras, recias cortezas, la hermosura inmaculada, igual que mi corazón y sentido cautivar pudo

esconderse entre vosotras para siempre?

Vosotros ojos, que más un duelo que ojos sois;

permaneced ligados por siempre a estas ramas.

Aquí, el noble corazón ahí se halla,

el que así el mío rompe,

aquí está la luz de mi sol,

esta es la clara vela del día,

la que ahuyenta a la noche,

que todo oscuro y negro transforma.

Si bien por lo demás soy inmortal, mas por ella muero lentamente.

Ay ninfa, que del amor

de un dios te has sustraído,

y por ello tu cuerpo hermoso

en un laurel se ha transformado,

Ya nunca volverá a ocurrir que no conduzca tu alabanza contigo al cielo,

con las hojas siempre quiero, o lucero mío, adornarme este pelo dorado. 
le crespe chiome, e bionde

più non riveggo, $\mathrm{e}$ ' 1 volto, $\mathrm{e}$ ' 1 bianco petto.

Ma del gentile aspetto

ogni sembianza si dilegua, e perde;

sol miro un arboscel fiorito, e verde.

\section{CORO}

O miserabil caso, o destin rio, che fe', che disse allora

l'innamorato dio?

\section{NUNZIO}

\section{All'alta novitate}

fermò repente il passo

e, confuso d'orrore e di pietate, restò per lungo spazio immobil sasso.

Poscia a le fronde amate

levando gl'occhi sospirosi, e molli

stese le braccia, e "1 nobil tronco avvinse

e mille volte ribacciollo, e strinse;

piangean dintorno le campagne, e i colli

sospiravan pietosi, e l'aure, e i venti

ed ei nel gran dolore

sciogliea sì mesti accenti,

ch'io sentii per pietà mancarmi il core;

ma vedete lui stesso

che verso noi se n' viene,

tutto carco di pene;

deh come fuor del luminoso volto

traspare il duol ch'ha dentr'al petto accolto.
La melena ondulada y rubia

ya no vuelvo a ver, ni el rostro, ni el blanco pecho;

sino que del amable aspecto

se desvanece y pierde todo semblante;

solo contemplo un arbolito florido y verde.

\section{CORO}

¡Caso miserable, destino perverso!

¿Qué hizo, qué dijo entonces

el Dios enamorado?

\section{MENSAJERO}

Delante de la gran novedad detuvo de repente el paso y confundido por el horror y la piedad se quedó largo rato como inmóvil piedra. Después hacia las frondas queridas levantando los ojos llenos de suspiros y lágrimas

extendió los brazos y el noble tronco rodeó, y mil veces lo besó y abrazó.

Alrededor lloraban los campos, y las

colinas

suspiraban con piedad, y el aire y los

vientos;

y él en el gran dolor

emitía tan melancólicos acentos

que sentí que el corazón me fallaba por la pena.

Pero lo veis en persona

que viene hacia nosotros

bien cargado de penas:

¡Ah, cómo desde el luminoso rostro se trasparenta el duelo, que acogió en su pecho! 
Diese meine Pflanze hier

Sol begrünt sein für und für,

Sol in Kält' und Hitze stehen ,

Für dem Wetter frei und los;

Donner, Blitz und harter Schloß

Sol bei ihr fürüber gehen.

Die Regenten dieser Welt

Und ein unverzagter Held,

Der sich ritterlich geschlagen

Unter seiner Feinde Schar,

Sol um sein sieghaftes Haar

Diese frische Zweige tragen.

Heerd' und Hirten sollen dir

Lassen deine grüne Zier:

Hier soll frei von allen Dingen

Nymph' und Göttin ihre Zeit

Lustig und in Fröhlichkeit,

$\mathrm{O}$ du edler Baum, verbringen.
Esta planta mía de aquí debe estar siempre verde, resistir al frío y al calor, libre y suelta ante cualquier clima; truenos, rayos y fuerte granizo deben pasar ante ella de largo. Los monarcas de este mundo y el más valiente héroe, vencido caballerescamente por la multitud de enemigos, alrededor de su cabellera triunfante estas ramas frescas portarán. Ejércitos y pastores respetarán tu verde ornamento: aquí, libre de todo, la diosa y ninfa su tiempo, divertida y con alegría, noble árbol, pasará. 


\section{APOLLO}

Dunque ruvida scorza chiuderà sempre la beltà celeste?

Lumi, voi che vedeste

l'alta beltà, ch'a lagrimar vi sforza, affisatevi pure in questa fronde: qui posa, e qui s'asconde il mio bene, il mio core, il mio tesoro, per cui ben, ch'immortal languisco, e moro.

Ninfa sdegnosa, e schiva, che fuggendo l'amor d'un dio del cielo

cangiasti in verde lauro il tuo bel velo,

non sia però ch'io non onori ed ami,

ma sempre al mio crin d'oro

faran ghirlanda le tue fronde, e rami; ma deh, s'in questa frond'odi il mio pianto, senti la nobil cetra

quai doni a te del ciel cantando impetra.

Non curi la mia pianta, o fiamma, o gelo,

sian del vivo smeraldo eterni i pregi

né l'offenda già mai l'ira del cielo.

I bei cigni di Dirce, e i sommi regi

di verdeggianti rami al crin famoso portin segno d'onor ghirlande, e fregi

gregge mai né pastor sia che noioso del verde manto suo la spogli, e prive; alla grat'ombra il dì lieto, e gioioso traggan dolce cantando, e ninfe, e dive.

\section{APOLO}

¿Entonces una áspera corteza

cerrará para siempre la belleza celeste?

Estrellas, vosotras que visteis

la gran belleza que os obliga a llorar

fijaos también en esta fronda:

aquí está y aquí se esconde

mi bien, mi corazón, mi tesoro,

por el que, aunque soy inmortal, languidezco y me muero.

Ninfa altiva y esquiva

que rehuyendo del amor de un Dios del

cielo

cambiaste en verde laurel tu hermoso

semblante

no vaya a suceder que yo no te honre y te ame,

sino siempre mi melena dorada

tendrá guirnaldas de tus frondas y ramas, pero si en esta fronda oyes mi llanto, escucha la noble cítara,

que al Cielo cantando regalos para ti implora:

Que no se preocupe mi planta ni del fuego ni del hielo,

que sus adornos sean eternamente verde esmeralda,

ni la perjudique nunca jamás la ira del Cielo.

Los hermosos Cisnes de Dirce y los sumos

Reyes

lleven como signo de honor guirnaldas y

adornos

de ramas verdes en el cabello famoso.

Nunca rebaño ni Pastor exista que molesto

de su manto verde la desnude y despoje:

a la agradable sombra el día alegre y

gozoso

pasen cantando dulcemente Ninfas y

Diosas. 


\section{CORO}

Bella ninfa fuggitiva, sciolta, e priva del mortal suo nobil velo godi pur pianta novella casta, e bella cara al mondo, e cara al cielo.

Tu non curi, e nembi e tuoni tu coroni cigni, regi, e dèi celesti geli il cielo, o "nfiammi, e scaldi, di smeraldi

lieta ogn'or t'adorni, e vesti. Godi pur de' doni egregi;

i tuoi pregi non t'invidio, e non desio: io se mai d'amor m'assale aureo strale non vo' guerra con un dio. S'a fuggir movo le piante vero amante, contra amor cruda, e superba, venir possa il mio crin d'auro non pur lauro, ma qual è più miser erba? Sia vil canna il mio crin biondo che l'immondo gregge ogn' or schianti, e dirame sia vil fien, ch'a i crudi denti degl'armenti tragga ogn'or l'avida fame.

\section{CORO}

Ma s'a' preghi sospirosi, amorosi, di pietà sfavillo, ed ardo, s'io prometto all'altrui pene dolce speme

con un riso, e con un guardo.

Non soffrir, cortese Amore, che '1 mio ardore prenda a scherno alma gelata; non soffrir, ch' in piaggia, o ' $\mathrm{n}$ lido cor infido m'abbandoni innamorata. Fa' ch'al foco de' miei lumi si consumi ogni gelo, ogni durezza; ardi poi quest'alma all'ora ch'altra adora, qual si sia la mia bellezza.

\section{CORO}

Hermosa Ninfa fugitiva, liberada y despojada de tu mortal y noble semblante, goza como planta nueva casta y hermosa querida por el mundo y querida por el cielo.

Tú no te preocupas de nimbos ni de truenos, tú coronas cisnes, Reyes y Dioses celestes

hielas el cielo, o lo enciendes y calientas, de esmeraldas

alegre siempre te adornas y vistes.

Goza por ende de los extraordinarios regalos;

tus calidades

no te envidio ni deseo:

yo, si alguna vez de Amor me ataca

el áurea flecha,

no quiero guerra con un Dios.

Si voy huyendo

del verdadero amante,

contra amor, cruel y soberbia,

que mi cabello dorado pueda tornarse

no en ya laurel

sino igual a la hierba más mezquina.

Que mi cabello rubio sea caña ruin

que el inmundo

rebaño siempre destroce y desparrame;

que sea heno ruin, al que el hambre codiciosa atraiga siempre

los dientes crueles de las manadas.

\section{CORO}

Pero si a los ruegos llenos de suspiros, de amor, resplandezco y me enciendo de piedad, si yo prometo a la pena ajena dulce esperanza con una risa y con una mirada, no temas, Amor cortés, que mi ardor ridiculice un alma helada, no temas que, en la playa o la costa, un corazón traidor me abandone enamorada.

Haz que al fuego de mis ojos se consuma cualquier frialdad, cualquier dureza, entonces deja arder esta alma que otra adora, cualquiera que sea, mi belleza. 


\section{DIE NYMPHEN UND HIRTEN (Tanz um}

den Baum)

O schöne Nymphe, freue dich,

Dein Leib der vor besorgte sich

Für Liebes-Übelthätern,

Nach dem er Laub und Schatten gibt,

So wird der schöne Baum geliebt

Von Menschen und von Göttern.

Kein Blitz ist, der dein Kleid zerbricht,

Du achtest keinen Regen nicht,

Blühst stets mit grünen Haaren,

Legst nimmer von dir deine Zier,

Bekränzest große Fürsten hier

Und auch der Götter Scharen.

Nun wachse fort, als wie du thust,

Geneuß mit Freuden deiner Lust

Und deiner schönen Gaben.

Wie aber, wo ja Amors Pfeil

Uns auch wird geben unser Theil,

Wolln ihn in Ehren haben.

Und trügen wir dann Liebesgunst,

Laß unsrer Augen treue Brunst

Der Liebsten Sinn durchbringen;

Laß unsers guten Herzens Pflicht,

Wie Eis, das von der Sonnen bricht,

Ihr hartes Herze zwingen.

Wo aber es sich auch begibt,

$\mathrm{Da}$ die von uns nicht wird geliebt,

Die uns liebt je auf Erden,

So laß dieß unser Haar allhier

An statt des Lorberbaumes Zier

In Heu verwandelt werde.

Nun grüne fort und mit dir auch

Der überedle Rautenstrauch;

Der uns erhelt das Leben

Der Himmel laß ihn seine Frucht,

Die manches krankes Land jetzt sucht,

Von Zeit zu Zeiten geben.

Nimm zu und wachse für und für,

O Rautenstrauch, der Felder Zier,

Für dem die Schlangen fliehen,

Der böse Lust und Schmerzen stillt,

Für dessen Kraft kein Gift was gilt

Und kann uns nicht durchziehen.

Nim zu und wachse für und für

Und deine Zweige neben dir,

Die alle Schönheit zieret,

Von denen einer sich jetzt gibt

Dem Löwen, der ihn herzlich liebt

Und hin in Hessen führet.

\section{LAS NINFAS Y LOS PASTORES (Baile}

alrededor del árbol)

Bella ninfa, alégrate,

tu cuerpo que antes se preocupaba

por malhechores de amor,

cuando de él brote sombra y follaje,

el bello árbol será amado

por hombres y por dioses.

No hay relámpago que rasgue tu vestido, tampoco a la lluvia atiendes;

siempre en flor con tu verde cabellera,

no te desprendes de tu adorno nunca,

coronas las testas de grandes príncipes

y también de multitud de dioses.

Sigue creciendo, pues, tal y como haces,

disfruta con gozo de tu placer

y de tus bellos dones.

Mas nosotros, ya que la flecha de Amor

también nuestra parte nos dará,

queremos nuestra honra mostrarle.

Y si con favor amoroso nos premiara, permite que el celo fiel de nuestros ojos traspase el sentido de la amada;

deja que el deber de nuestro buen corazón, igual que el hielo, que se quiebra con el sol, penetre en su duro corazón.

Mas si bien ocurriera,

que no fuera amada por nosotros,

la que en la tierra más nos amara,

haz entonces que nuestro cabello

en vez de adornar el árbol del laurel

en paja se convierta.

Ahora continúa floreciendo y también

contigo

el más noble ramo de arbusto

que la vida nos ilumina;

el cielo permite que su fruto

que ciertas enfermas tierras ahora buscan de tiempo en tiempo dé.

Hazte grande y crece más y más,

$\mathrm{O}$, ramo de arbusto, adorno de los campos, del que las serpientes huyen,

el que el mal sentir y dolores calma,

Contra cuyo poder no existe veneno

efectivo

que nos pueda traspasar.

Hazte grande y crece más y más,

$\mathrm{Y}$ tus ramas junto a ti,

que toda belleza adornan,

de las que una ahora al león se ofrece,

al que ama con afecto

y a Hessen guía. 
O schöner Frühling, freue dich,

Der Blumen Luft erhebe sich,

Die Vögel müssen singen;

Der Zweig, so dich, o Löw', ergeßt, den Venus in dein Land versetzt,

Wird neue Zweige bringen.

Wir sehen schon, wie nach der Zeit,

Wann Jupiter den harten Streit

Durch Deutschland noch wird stillen,

Wir sehen, wie der Rauten Zier

Mit grüner Luft wird für und für

Feld, Berg und Thal erfüllen.
Bella primavera, alégrate,

que el aroma de las flores se eleve;

los pájaros han de cantar;

la rama que a ti, o león, tanto deleita, la que Venus trasladó a tus tierras; nuevas ramas dará.

Y ya vemos, como pasado un tiempo, cuando Júpiter la dura batalla en Alemania apacigua, vemos, cómo el adorno de arbusto con su verde aire cada vez más campos, montes y valles colma. 
